\title{
Cerebral blood flow velocity monitoring in pyogenic meningitis
}

\author{
Dayeel Goh, Robert A Minns
}

\begin{abstract}
Transcranial Doppler ultrasound monitoring of cerebral blood flow velocity (CBFV) was performed on 17 children (age range 8 days to 6 years) with pyogenic meningitis. Serial measurements of the peak systolic, end diastolic, mean flow velocity, and resistance index (equal to peak systolic velocity minus end diastolic velocity divided by peak systolic velocity) were obtained over the period of their hospital admission. In all 16 survivors there was a significant decrease in the final resistance index compared with the initial resistance index due to a significant increase in the end diastolic velocity. There was a significant increase in the final mean flow velocity. In four patients the decrease in intracranial pressure and increase in cerebral perfusion pressure after mannitol infusions was accompanied by a corresponding decrease in resistance index and increase in mean flow velocity. A pressure passive CBFV response with a significant linear correlation for resistance index/mean arterial pressure may suggest a loss of cerebrovascular autoregulation. These results suggest that in the early phase increased cerebrovascular resistance may contribute to a relative impairment of cerebral perfusion. Non-invasive monitoring by transcranial Doppler ultrasound may be helpful for early detection of deterioration in cerebral haemodynamic trends.
\end{abstract}

\section{(Arch Dis Child 1993;68:111-9)}

Bacterial meningitis is one of the most serious diseases in early childhood with a reported overall mortality rate of $8.6 \%$ in the first year of life. ${ }^{1}$ Although mortality rates have improved, there is still a considerable long term morbidity ranging from 10 to $15 \% .^{2}$ Impaired cerebral perfusion resulting from a variety of factors plays an important part in the pathogenesis of cerebral injury in meningitis. ${ }^{3} \mathrm{~A}$ minimum cerebral perfusion pressure of $30 \mathrm{mmHg}$ was found to be an important factor for survival in children who were comatose from severe central nervous system infection. ${ }^{45}$ Minns et al have reported increased cerebrospinal fluid pressure to be a common accompaniment of pyogenic meningitis. ${ }^{6}$ Increased intracranial pressure is likely to be an early feature in the pathophysiology of pyogenic meningitis ${ }^{35}$ and contributes to reduced cerebral perfusion pressure. Cerebral infarction and oedema, shown by computed tomography, were reported to be predictive of a poor outcome whereas enlarged ventricular and subarachnoid spaces and subdural effusions were of no predictive value. ${ }^{7}$ Monitoring cerebrohaemodynamic changes may be important for early detection of cerebral perfusion compromise with the aim of preventing further cerebral insult.

Although there are a number of techniques available to measure cerebral perfusion, most are either invasive or not practical for continuous monitoring purposes. Transcranial Doppler ultrasound provides a non-invasive means of measuring cerebral blood flow velocity (CBFV) in the basal cerebral arteries. ${ }^{8}$ Analysis of changes in the CBFV waveforms has been widely reported in a number of clinical disorders such as hydrocephalus, ${ }^{9-11}$ subarachnoid haemorrhage, ${ }^{12}$ brain stem death, ${ }^{13}$ and neonatal cerebrohaemodynamics and in normal neonates. ${ }^{14}$ There have, however, only been two published reports on CBFV changes in childhood meningitis. ${ }^{15} 16$ McMenamin and Volpe reported a depressed mean tlow velocity associated with increased intracranial pressure in four older infants (mean age 5.75 months) during the initial phase of the illness. ${ }^{15}$ In contrast, decreased mean flow velocity and increased intracranial pressure were not present in their four newborn patients. Bode and Harders, however, reported a marked (up to fivefold) and persistent increased mean flow velocity in the middle cerebral artery in three of their 14 patients with meningitis, which was attributed to significant vessel narrowing causing secondary ischaemic damage as these patients had a poor outcome. ${ }^{16}$ The moderately increased flow velocities in the 11 patients with a favourable outcome was ascribed to increased cerebral blood flow.

With increased distal resistance to flow, the Pourcelot resistance index increases steadily as the diastolic velocity decreases, ${ }^{17}$ for example, with steady increase in intracranial pressure in hydrocephalic children, ${ }^{11}$ and with intracranial circulatory arrest when intracranial pressure approaches the systemic diastolic blood pressure, diastolic CBFV approaches zero. ${ }^{13}$ The resistance index was also significantly related to increased intracranial pressure in comatose adults $^{18}$ and to reduced cerebral perfusion pressure due to increasing intracranial pressure in an experimental animal model. ${ }^{19}$ Changes in mean flow velocity may, however, be due to changes in mean volume flow $^{20}$ or due to alteration in the calibre of the insonated vessel as a result of vasospasm or stenosis. After a subarachnoid haemorrhage, a mean flow velocity $<120 \mathrm{~cm} / \mathrm{s}$ is suggestive of significant vasospasm accompanied by low volume flow. ${ }^{12}$

With the obvious practical advantages of 
transcranial Doppler ultrasound as an easily repeatable, safe technique, it is now becoming widely applied in bedside monitoring of cerebrohaemodynamic trends in neurointensive care management. ${ }^{21}$ Careful interpretation of changes in CBFV indices is required in various clinical situations, however. ${ }^{14}$ We describe our experience in using transcranial Doppler ultrasound as a non-invasive method of monitoring cerebrohaemodynamic changes in 17 children who were admitted with pyogenic meningitis.

\section{Patients and methods}

Seventeen patients (nine boys, eight girls) who were admitted with a diagnosis of pyogenic meningitis were monitored during the course of their admission by transcranial Doppler ultrasound. Table 1 summarises their clinical details. Their age range was from 8 days to 6 years; four patients were less than 3 months old (group I) and 13 patients were between 6 months and 6 years old (group II). The patients were allocated to two groups as the normal range of CBFV data is age dependent ${ }^{10-22}$ (table 2) and also to allow comparison with previously published data. ${ }^{15}$ Initial transcranial Doppler ultrasound examination was performed within the first two days after admission and then repeated at intervals during their admission, more often during the early days. Three patients were transferred from other hospitals after not improving satisfactorily. Three patients required ventilatory and intensive care support on admission. In four patients CBFV recordings with simultaneous intracranial pressure and cerebral perfusion pressure measurements before and after mannitol infusions were obtained. Cerebral imaging by transfontanelle sonography was performed in 10 infants and computed tomography scans in three children with clinical signs of increased intracranial pressure or with persistent pyrexia and irritability.

The organisms isolated from the cerebrospinal fluid were group B haemolytic streptococci (two), Escherichia coli (one), Neisseria meningitidis (five), Haemophilus influenzae type b (six),
Streptococcus pneumoniae (one), and Salmonella enteritidis (one). In one patient (No 12) who had received antibiotics before admission and before cerebrospinal fluid was obtained (lumbar puncture deferred until the second day), no specific bacterial or viral agent was isolated and counter current immunoelectrophoresis antigen screening was also negative. The cerebrospinal fluid leucocyte count was markedly increased $\left(4.5 \times 10^{9} / 1 ; 84 \%\right.$ neutrophils $)$ and he showed a rapid clinical response to antibiotic treatment, thus suggesting most likely a bacterial aetiology. Only one patient (patient No 1, a 2 week old neonate with group $B$ haemolytic streptococcal infection) died during this study.

\section{CBFV MEASUREMENTS}

CBFV was measured in the middle cerebral artery using a 2 or $4 \mathrm{MHz}$ pulsed wave probe attached to a portable Doppler unit (Decoder, Doptek Ltd). The middle cerebral artery is a major branch of the carotid system and is most easily and reliably insonated at a minimum angle from the temporal position (at a depth ranging from 2.5 to $5 \mathrm{~cm}$ in our patients) using the technique described by Aaslid et al. ${ }^{8}$ The

Table 2 Normal ranges for resistance index and mean flow velocity

\begin{tabular}{lll}
\hline Age & Resistance index & $\begin{array}{l}\text { Mean flow } \\
\text { velocity } \\
(\mathrm{cm} / \mathrm{s})\end{array}$ \\
\hline Bode and Wais $22: *$ & \\
$0-90$ days & $0.62-0.80$ & $10-62$ \\
$3-11.9$ months & $0.58-0.62$ & $46-102$ \\
$1-2.9$ years & $0.40-0.59$ & $65-105$ \\
$3-5.9$ years & $0.54(0.4)-0.58(0.62)$ & $74-114$ \\
$6-9.9$ years & $0.46-0.54$ & $79-115$ \\
$10-18$ years & $0.53-0.54$ & $59-103$
\end{tabular}

Chadduck and Seibert ${ }^{10}$

Term infants ( $>34$ weeks' gestation): $0.71(0.07) \dagger$

27 children (18 months-16 years): $0 \cdot 50(0 \cdot 15) \dagger$

Goh and Minns (unpublished data)

11 children (21-112 months): $0 \cdot 45-0 \cdot 61$

${ }^{*}$ Calculated normal ranges (mean (2SD)) from 112 healthy

children (aged 1 day-18 years)

†Nean $(\mathrm{SD})$ resistance index values.
Normal range of resistance index values.

Table 1 Clinical details of patient

\begin{tabular}{|c|c|c|c|c|c|c|c|c|}
\hline \multirow[t]{2}{*}{$\begin{array}{l}\text { Patient } \\
\text { No }\end{array}$} & \multirow[t]{2}{*}{ Age } & \multirow[t]{2}{*}{ Sex } & \multirow[t]{2}{*}{$\begin{array}{l}\text { Cerebrospinal fluid } \\
\text { organism }\end{array}$} & \multicolumn{2}{|c|}{$\begin{array}{l}\text { Diagnostic } \\
\text { cerebrospinal fluid }\end{array}$} & \multirow[t]{2}{*}{$\begin{array}{l}\text { (jlucose } \\
(\text { mmolll })\end{array}$} & \multirow[t]{2}{*}{ Radiological findings } & \multirow[t]{2}{*}{$\begin{array}{l}\text { Outcome at } \\
\text { discharge }\end{array}$} \\
\hline & & & & $\begin{array}{l}\text { Leucocytes } \\
\left(\times 10^{\prime \prime} / l\right)\end{array}$ & $\begin{array}{l}\text { Protein } \\
(\mathrm{g} / \mathrm{l})\end{array}$ & & & \\
\hline $\begin{array}{r}1 \\
2 \\
3 \\
4 \\
5 \\
6 \\
7 \\
8 \\
9 \\
10 \\
11 \\
12 \\
13\end{array}$ & $\begin{array}{r}2 \text { weeks } \\
8 \text { days } \\
13 \text { days } \\
11 \text { weeks } \\
9 \text { months } \\
8 \text { months } \\
8 \text { months } \\
11 \text { months } \\
26 \text { months } \\
8 \text { months } \\
23 \text { months } \\
6 \text { months } \\
19 \text { months }\end{array}$ & $\begin{array}{l}\mathrm{F} \\
\mathrm{M} \\
\mathrm{F} \\
\mathrm{F} \\
\mathrm{M} \\
\mathrm{M} \\
\mathrm{F} \\
\mathrm{M} \\
\mathrm{M} \\
\mathrm{F} \\
\mathrm{F} \\
\mathrm{M} \\
\mathrm{M}\end{array}$ & $\begin{array}{l}\text { Group B streptococcus } \\
\text { Escherichia coli } \\
\text { Group B streptococcus } \\
\text { Haemophilus influenzae } \\
\text { Neisseria meningitidis } \\
\text { Haemophilus influenzae } \\
\text { Haemophilus influenzae } \\
\text { Neisseria meningitidis } \\
\text { Haemophilus influenzae } \\
\text { Neisseria meningitidis } \\
\text { Neisseria meningitidis } \\
\overline{\text { Haemophilus influenzae }}\end{array}$ & $\begin{array}{r}0 \cdot 5 \\
10 \cdot 4 \\
0 \cdot 6 \\
1 \cdot 4 \\
7 \cdot 1 \\
4 \cdot 9 \\
1.9 \\
20 \cdot 8 \\
0 \cdot 7 \\
6.7 \\
10 \cdot 0 \\
4 \cdot 5 \\
1 \cdot 6\end{array}$ & $\begin{array}{c}8.9 \\
4 \cdot 18 \\
\text { Blood } \\
0.97 \\
1.38 \\
0.92 \\
0.54 \\
2.92 \\
1 \cdot 28 \\
1.21 \\
-2 \cdot 3 \\
4 \cdot 06\end{array}$ & $\begin{array}{l}\text { None } \\
2.3 \\
\text { Stained } \\
<0.5 \\
<0.3 \\
<0.5 \\
<3.5 \\
<0.5 \\
<0.9 \\
<1.6 \\
- \\
2.9 \\
<0.5\end{array}$ & $\begin{array}{l}\text { Ultrasound: oedema, focal echogenicity } \\
\text { Ultrasound: normal } \\
\text { Ultrasound: normal } \\
\text { Ultrasound: bilateral subdural effusions } \\
\overline{\text { Ultrasound: bilateral subdural effusions }} \\
\overline{-} \\
\overline{-} \\
\overline{\text { Ultrasound:normal }} \\
\overline{\text { Ultrasound:normal }} \\
\text { Computed tomography, magnetic resonance } \\
\text { imaging scans: normal }\end{array}$ & $\begin{array}{l}\text { Died } \\
\text { Normal } \\
\text { Normal } \\
\text { Normal } \\
\text { Normal } \\
\text { Normal } \\
\text { Normal } \\
\text { Normal } \\
\text { Normal } \\
\text { Normal } \\
\text { Normal } \\
\text { Normal } \\
\text { Mild ataxia }\end{array}$ \\
\hline 14 & 7 months & $M$ & Streptococcus pneumoniae & $11 \cdot 8$ & $33 \cdot 0$ & 0.5 & $\begin{array}{l}\text { Ultrasound and computed tomography } \\
\text { scans: bilateral subdural effusions (right } \\
\text { increased density); communicating } \\
\text { hydrocephalus }\end{array}$ & $\begin{array}{l}\text { Left focal seizures, } \\
\text { mild left weakness }\end{array}$ \\
\hline 15 & 8 months & $\mathbf{F}$ & Haemophilus influenzae & $12 \cdot 4$ & $0 \cdot 75$ & $4 \cdot 0$ & $\begin{array}{l}\text { Ultrasound: widened subdural spaces, } \\
\text { echogenic cortical sulci }\end{array}$ & Normal \\
\hline 16 & 6 months & $\mathbf{M}$ & Neisseria meningitidis & $10 \cdot 1$ & $0 \cdot 42$ & $3 \cdot 2$ & $\begin{array}{l}\text { Ultrasound: bilateral subdural effusions, } \\
\text { slight ventricular dilatation }\end{array}$ & Normal \\
\hline 17 & 6 years & $\mathbf{F}$ & Salmonella enteritidis & $10 \cdot 4$ & $2 \cdot 66$ & $<0.5$ & $\begin{array}{l}\text { Computed tomography scan: mild } \\
\text { prominent ventricles, no focal lesion }\end{array}$ & Normal \\
\hline
\end{tabular}


Decoder performs real time spectral analysis on the Doppler signals which were recorded on an audio cassette deck (Yamaha KX500). Transcranial Doppler ultrasound examinations were carried out at the bedside when patients were asleep or quiet. CBFV data obtained when patients were uncooperative or unsettled were discarded as movement or crying causes unstable waveforms. Values of the time averaged mean flow velocity, peak systolic velocity, end diastolic velocity, and the resistance index were obtained. Each calculated value was obtained from the mean of the least 10 consecutive cardiac cycles with waveforms of good quality. The outline of the maximum velocity envelope was manually traced on screen using a light pen and the Doppler indices were calculated by software in the Decoder. This method allows accurate waveform measurements to be made while eliminating background noise in the spectrogram or waveforms distorted by patient or probe movement.

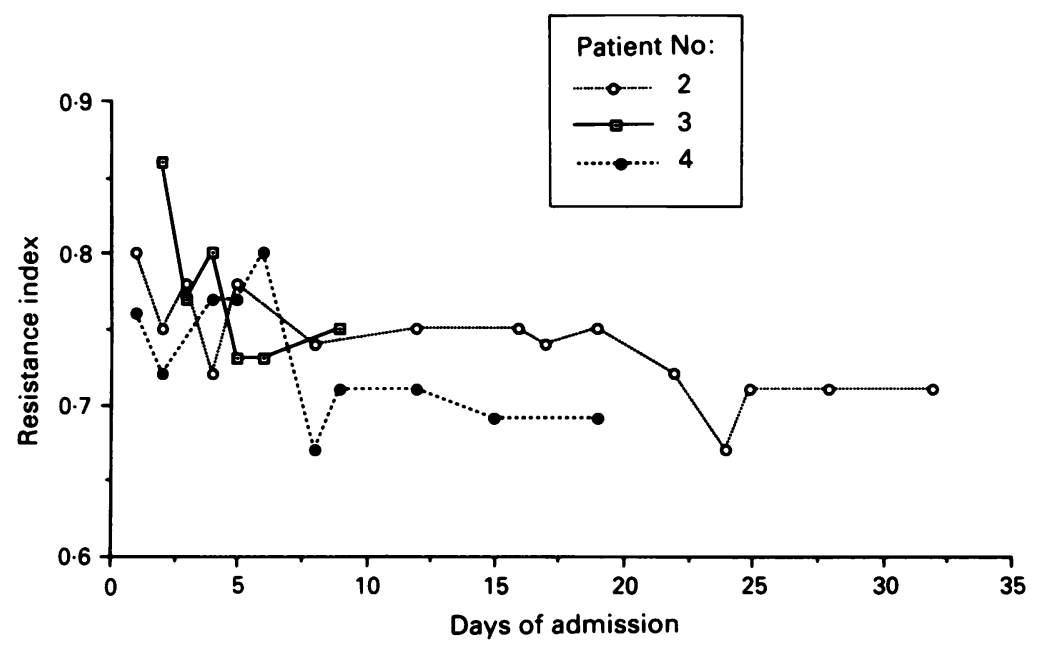

Figure 1 Serial resistance index values in three group I $(<3$ months old ) survivors showing a decrease in resistance index values with clinical improvement. Patient No 2 had a relapse after 10 days of intravenous antibiotics but showed a good response with complete resolution of infection after a further three weeks of treatment. Patient No 4 developed small bilateral subdural effusions which gradually resolved without specific intervention. All three patients had resistance index values within the normal range for age (table 2) at discharge.

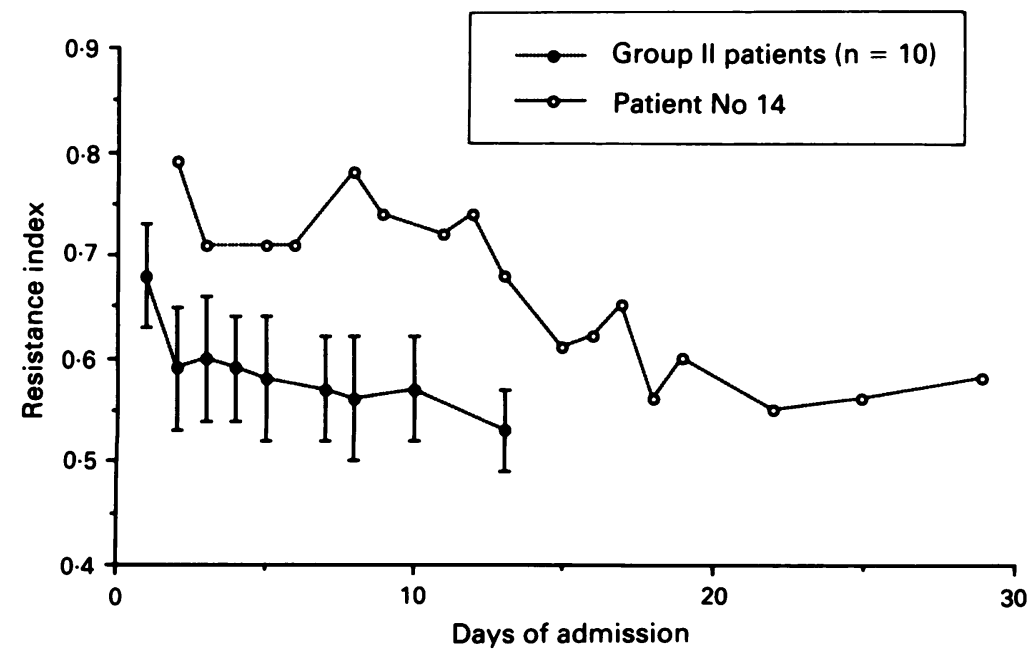

Figure 2 Serial mean (SD) resistance index values from 10 group II patients (older infants and children) who had an uncomplicated recovery while receiving intravenous antibiotics, showing a steady decrease in the mean resistance index with improvement. In contrast, patient No 14 with bilateral subdural effusions and hydrocephalus, who required intrathecal penicillin, had more persistently increased resistance index values which also gradually decreased to the normal range for age with recovery.
Factors known to influence the CBFV waveform include the distal impedance to flow, the carbon dioxide tension $\left(\mathrm{PaCO}_{2}\right)$, the calibre of the insonated blood vessel, and the input from the systemic circulation. In this study $\mathrm{PaCO}_{2}$ measurement was not carried out in most of the patients as they did not require ventilatory support; these patients were studied under quiet bedside conditions, breathing spontaneously in room air. In those who were ventilated, $\mathrm{PaCO}_{2}$ was maintained within the normal range $(3 \cdot 5-5 \cdot 5 \mathrm{kPa})$. None of our patients had a patent ductus or other congenital heart lesion.

\section{CBFV INDICES}

As a ratio, the resistance index, which is equal to the peak systolic velocity minus end diastolic velocity divided by the peak systolic velocity, adapted as an index of cerebrovascular impedance, minimises the error due to a varying angle of insonation. Archer et al have shown a significant correlation between decreasing resistance index and decreased distal resistance due to hypercapnia induced vasodilatation. ${ }^{23}$ The resistance index is normally higher in neonates and rapidly decreases over the first year of life; the normal range for the first three months is between 0.62 and 0.8 and from later infancy throughout childhood is between 0.4 and 0.62 (see table 2).

Measured values of absolute velocity indices such as the mean flow velocity, peak systolic velocity, or end diastolic velocity are more dependent on variability in the angle of insonation. In a continuous monitoring situation where the transcranial Doppler ultrasound probe is fixed or over short periods of time when there are no changes in its position, a constant angle of insonation may be more reliably assumed. Under these conditions, a reliable correlation has been shown for a percentage change in mean flow velocity and in cerebral blood flow measured using intravenous xenon-133, though correlation for absolute measurements are less reliable due to wide interpatient variations. ${ }^{20}$

The paired $t$ test was used to compare changes between the initial and final (obtained before discharge) CBFV indices in the 16 survivors. Linear correlation between resistance index and mean flow velocity with intracranial pressure, cerebral perfusion pressure, and mean arterial pressure was calculated in five patients where these measurements were available.

\section{Results}

RESISTANCE INDEX

In 11 of the patients there was an increased resistance index (greater than the mean plus two standard deviations for age) at the initial transcranial Doppler ultrasound examination (table 3). Serial measurements of the resistance index decreased with resolution of infection and clinical improvement (fig 1, group I; fig 2, group II) and resistance index values were within the normal range at discharge in all survivors (table 3 ). There was a highly significant decrease in resistance index $(p<0.001)$ from 
Table 3 Initial and final cerebral blood flow velocity indices in 16 survivors

\begin{tabular}{|c|c|c|c|c|c|c|c|c|c|}
\hline $\begin{array}{l}\text { Patient } \\
\text { No }\end{array}$ & Age & $\begin{array}{l}\text { Initial } \\
\text { resistance } \\
\text { index }\end{array}$ & $\begin{array}{l}\text { Final } \\
\text { resistance } \\
\text { index }\end{array}$ & $\begin{array}{l}\text { Initial mean } \\
\text { flow velocity } \\
(\mathrm{cm} / \mathrm{s})\end{array}$ & $\begin{array}{l}\text { Final mean } \\
\text { flow velocity } \\
(\mathrm{cm} / \mathrm{s})\end{array}$ & $\begin{array}{l}\text { Initial peak } \\
\text { systolic velocity } \\
(\mathrm{cm} / \mathrm{s})\end{array}$ & $\begin{array}{l}\text { Final peak } \\
\text { systolic velocity } \\
(\mathrm{cm} / \mathrm{s})\end{array}$ & $\begin{array}{l}\text { Initial end } \\
\text { diastolic velocity } \\
(\mathrm{cm} / \mathrm{s})\end{array}$ & $\begin{array}{l}\text { Final end } \\
\text { diastolic velocity } \\
(\mathrm{cm} / \mathrm{s})\end{array}$ \\
\hline $\begin{array}{r}2 \\
3 \\
4 \\
5 \\
6 \\
7 \\
8 \\
9 \\
10 \\
11 \\
12 \\
13 \\
14 \\
15 \\
16 \\
17\end{array}$ & $\begin{array}{r}8 \text { days } \\
13 \text { days } \\
11 \text { weeks } \\
9 \text { months } \\
8 \text { months } \\
8 \text { months } \\
11 \text { months } \\
26 \text { months } \\
8 \text { months } \\
23 \text { months } \\
6 \text { months } \\
19 \text { months } \\
7 \text { months } \\
8 \text { months } \\
6 \text { months } \\
6 \text { years }\end{array}$ & $\begin{array}{l}0.80 \\
0.86 \\
0.76 \\
0.59 \\
0.66 \\
0.72 \\
0.58 \\
0.67 \\
0.61 \\
0.75 \\
0.64 \\
0.68 \\
0.79 \\
0.69 \\
0.64 \\
0.73\end{array}$ & $\begin{array}{l}0.71 \\
0.75 \\
0.69 \\
0.49 \\
0.52 \\
0.61 \\
0.56 \\
0.54 \\
0.50 \\
0.53 \\
0.50 \\
0.60 \\
0.58 \\
0.59 \\
0.55 \\
0.52\end{array}$ & $\begin{array}{l}41 \cdot 5 \\
29 \cdot 3 \\
40 \cdot 4 \\
71 \cdot 7 \\
55 \cdot 9 \\
49 \cdot 6 \\
68 \cdot 2 \\
65 \cdot 3 \\
89 \cdot 8 \\
40 \cdot 9 \\
68 \cdot 0 \\
69 \cdot 2 \\
37 \cdot 2 \\
67 \cdot 3 \\
81 \cdot 8 \\
46 \cdot 3\end{array}$ & $\begin{array}{r}43 \cdot 8 \\
37 \cdot 9 \\
68 \cdot 0 \\
82 \cdot 0 \\
56 \cdot 9 \\
70 \cdot 6 \\
83.0 \\
89 \cdot 8 \\
85 \cdot 4 \\
73 \cdot 2 \\
75 \cdot 4 \\
57 \cdot 4 \\
76.6 \\
71.0 \\
77 \cdot 9 \\
102.0\end{array}$ & $\begin{array}{r}81 \cdot 0 \\
67 \cdot 8 \\
71 \cdot 3 \\
109 \cdot 0 \\
95 \cdot 8 \\
88 \cdot 5 \\
108 \cdot 0 \\
122 \cdot 0 \\
145 \cdot 4 \\
80 \cdot 1 \\
110 \cdot 0 \\
124 \cdot 0 \\
80 \cdot 8 \\
120 \cdot 1 \\
141 \cdot 2 \\
98 \cdot 1\end{array}$ & $\begin{array}{r}78 \cdot 0 \\
37 \cdot 9 \\
110 \cdot 0 \\
113.0 \\
81.9 \\
108 \cdot 2 \\
117 \cdot 0 \\
129 \cdot 0 \\
120.8 \\
105 \cdot 5 \\
106.0 \\
92.3 \\
117.8 \\
112.3 \\
113.9 \\
159.6\end{array}$ & $\begin{array}{r}16 \cdot 0 \\
9 \cdot 5 \\
17 \cdot 3 \\
46 \cdot 0 \\
32 \cdot 8 \\
25 \cdot 1 \\
45 \cdot 0 \\
40 \cdot 4 \\
56 \cdot 9 \\
19 \cdot 1 \\
40 \cdot 0 \\
40 \cdot 0 \\
17 \cdot 8 \\
37 \cdot 9 \\
49 \cdot 4 \\
25 \cdot 7\end{array}$ & $\begin{array}{l}22 \cdot 0 \\
16 \cdot 0 \\
32 \cdot 4 \\
57 \cdot 0 \\
37 \cdot 3 \\
42 \cdot 6 \\
51 \cdot 0 \\
57 \cdot 3 \\
60 \cdot 6 \\
48 \cdot 1 \\
52 \cdot 4 \\
35 \cdot 0 \\
49 \cdot 1 \\
45 \cdot 4 \\
51 \cdot 0 \\
73 \cdot 5\end{array}$ \\
\hline $\begin{array}{l}\text { Mean (SD) value } \\
\text { p Value }\end{array}$ & & $\begin{array}{l}0 \cdot 70(0.08) \\
<0.001\end{array}$ & $0.58(0.08)$ & $\begin{array}{l}57 \cdot 6(17 \cdot 5) \\
<0 \cdot 01\end{array}$ & $71.9(16.5)$ & $\begin{array}{c}102.7(23.8) \\
0.39(\mathrm{NS})^{*}\end{array}$ & $108 \cdot 4(21 \cdot 4)$ & $\begin{array}{l}32 \cdot 4(14 \cdot 0) \\
0 \cdot 001\end{array}$ & $45 \cdot 7(14 \cdot 6)$ \\
\hline
\end{tabular}

$\mathrm{NS}=$ not significant .

paired $t$ test analysis of initial and final resistance index values in the 16 survivors. In the group I survivors the mean resistance index decreased from 0.81 to 0.72 , and in group II survivors the mean (SD) resistance index decreased from 0.67 $(0.06)$ to $0.545(0.04)$. The decrease in resistance index was mainly due to a significant increase in end diastolic velocity $(p=0.001)$ rather than to a change in peak systolic velocity (not statistically significant). Figure 2 shows the serial mean (SD) resistance index values of 10 group II patients who responded fully to intravenous antibiotic treatment. In contrast, serial resistance index values were more persistently increased in one patient with subdural effusions who required five doses of intrathecal penicillin in addition to intravenous antibiotics. There was no difference in the pattern of resistance index change between group I and II patients.

\section{MEAN FLOW VELOCITY}

Three patients had an initial mean flow velocity less than the normal range for age. ${ }^{22}$ Overall, the final mean flow velocity in the 16 survivors was significantly increased compared with the initial mean flow velocity $(\mathrm{p}<0.01)$ on paired $t$ test analysis, which may suggest an overall increased mean cerebral blood flow with recovery from infection compared with initial values at admission. Two patients in our study had a mean flow velocity $>120 \mathrm{~cm} / \mathrm{s}$ on one occasion each; patient No 11 on day $3(120.2 \mathrm{~cm} / \mathrm{s})$ and patient No 17 on day $2(132.3 \mathrm{~cm} / \mathrm{s})$. The increased mean flow velocity values did not persist in these two patients, however, and were within the normal range on the next day. In individual patients serial mean flow velocity values on a day to day basis were more variable compared with a more consistent decreasing pattern for serial resistance index values.

\section{CHANGES IN CBFV DUE TO MANNITOL}

In three patients simultaneous transcranial Doppler ultrasound and intracranial pressure recordings were carried out on the day of admission before and after mannitol infusions (table 4). In these patients the cerebral perfusion pressure increased as the intracranial pressure decreased after the mannitol infusions with accompanying improvement in CBFV indices, as the resistance index decreased and mean flow velocity increased. In patient No 16 lumbar puncture was deferred until after the mannitol infusion when the resistance index had decreased from 0.64 to 0.59 , and the mean flow velocity increased from $81 \cdot 8$ to $96 \cdot 9 \mathrm{~cm} / \mathrm{s}$.

\section{CASE DESCRIPTIONS}

Patient No 15 was admitted in a drowsy and lethargic state with a marked bulging fontanelle. At diagnostic lumbar puncture, the cerebrospinal fluid pressure measured by a non-displacement strain gauge pressure transducer method (Gaeltec Ltd) was increased with C waves at a mean of $19 \mathrm{~mm} \mathrm{Hg}$, and the cerebral perfusion pressure was $53 \mathrm{~mm} \mathrm{Hg}$. With a mannitol infusion over 30 minutes and a bolus dose of intravenous frusemide while leaving the spinal needle in position, the cerebrospinal fluid pressure gradually decreased to $10 \mathrm{~mm} \mathrm{Hg}$. After the mannitol infusion, the resistance index decreased from 0.69 to 0.60 and the mean flow velocity had increased from $68 \cdot 1$ to $91 \cdot 6$ $\mathrm{cm} / \mathrm{s}$ when the cerebral perfusion pressure had increased to $62 \mathrm{~mm} \mathrm{Hg}$.

Table 4 Changes in intracranial pressure, cerebral perfusion pressure, and CBFV indices before and after mannitol infusions in four patients. Values given as before mannitollafter mannitol

\begin{tabular}{lllllllll}
\hline $\begin{array}{l}\text { Patient } \\
\text { No }\end{array}$ & Age & $\begin{array}{l}\text { Mean arterial } \\
\text { pressure } \\
(\mathrm{mmHg})\end{array}$ & $\begin{array}{l}\text { Intracranial } \\
\text { pressure } \\
(\mathrm{mmHg})\end{array}$ & $\begin{array}{l}\text { Cerebral perfusion } \\
\text { pressure } \\
(\mathrm{mmHg})\end{array}$ & $\begin{array}{l}\text { Resistance } \\
\text { index }\end{array}$ & $\begin{array}{l}\text { Mean flow } \\
\text { velocity } \\
(\mathrm{cm} / \mathrm{s})\end{array}$ & $\begin{array}{l}\text { Peak systolic } \\
\text { velocity } \\
(\mathrm{cm} / \mathrm{s})\end{array}$ & $\begin{array}{l}\text { End diastolic } \\
\text { velocity } \\
(\mathrm{cm} / \mathrm{s})\end{array}$ \\
\hline 11 & 23 months & $69 / 68$ & $28 / 10$ & $41 / 58$ & $0 \cdot 82 / 0 \cdot 67$ & $36 \cdot 7 / 59 \cdot 0$ & $78 \cdot 5 / 106 \cdot 0$ & $12 \cdot 2 / 34 \cdot 4$ \\
15 & 8 months & $72 / 72$ & $19 / 10$ & $53 / 62$ & $0 \cdot 69 / 0 \cdot 60$ & $68 \cdot 1 / 91 \cdot 6$ & $120 \cdot 1 / 139 \cdot 1$ & $37 \cdot 1 / 54 \cdot 5$ \\
16 & 6 months & $81 / 62$ & -117 & -145 & $0.64 / 0 \cdot 59$ & $81 \cdot 8 / 96 \cdot 9$ & $141 \cdot 2 / 156 \cdot 0$ & $49 \cdot 4 / 61 \cdot 7$ \\
17 & 6 years & $65 / 77$ & $28 / 10$ & $37 / 67$ & $0 \cdot 73 / 0 \cdot 51$ & $46 \cdot 3 / 132 \cdot 3$ & $98 \cdot 1 / 197$ & $25 \cdot 7 / 98 \cdot 8$ \\
\hline
\end{tabular}


Patient No 17 was admitted in an unconscious state, only flexing to pain with upward ocular deviation. An emergency computed tomography scan was reported to show only mildly prominent ventricles with mild communicating hydrocephalus, no focal lesions, and no evidence on scan of significant cerebral oedema or increased intracranial pressure. Her initial resistance index of 0.73 was markedly increased, however, and the initial mean flow velocity of $46.3 \mathrm{~cm} / \mathrm{s}$ was also much reduced for her age. Lumbar puncture was performed with caution using the technique as described; the opening cerebrospinal fluid pressure was increased at a mean of $28 \mathrm{~mm} \mathrm{Hg}$ with $\mathrm{C}$ waves and a wide pulse pressure, and the cerebral perfusion pressure was only $37 \mathrm{~mm} \mathrm{Hg}$. The spinal needle was removed only when the cerebrospinal fluid pressure had decreased gradually to $6 \mathrm{~mm} \mathrm{Hg}$ over an hour with mannitol infusion and frusemide, and intermittent small incremental drainage of cerebrospinal fluid. Twelve hours later at repeat lumbar puncture, the cerebrospinal fluid pressure had decreased to $10 \mathrm{~mm} \mathrm{Hg}$, the resistance index had decreased to 0.51 , and the mean flow velocity was $132 \cdot 3 \mathrm{~cm} / \mathrm{s}$. Figure 3 shows the cerebrospinal fluid pressure recordings, cerebral perfusion pressure, and corresponding CBFV indices at the initial and repeat lumbar puncture 12 hours later.

Overall in these four patients there was a significant correlation between resistance index and intracranial pressure $(\mathrm{r}=0.81 ; \mathrm{p}<0.05)$, resistance index and cerebral perfusion pressure $(\mathrm{r}=-0.9 ; \mathrm{p}<0.01)$, and mean flow velocity and cerebral perfusion pressure $(r=0.88 ; \mathrm{p}<0.01)$. There was no significant correlation between resistance index and mean arterial pressure, or mean flow velocity and mean arterial pressure.

PRESSURE PASSIVITY

A 2 week old girl (patient No 1) with group B haemolytic streptococcal meningitis and septicaemia required early ventilation and inotrope support in addition to systemic antibiotics, dexamethasone, and anticonvulsants for an increasing frequency of apnoeic episodes and a poor peripheral circulatory state. A cerebral ultrasound scan showed collapsed lateral and third ventricles with increased echogenic areas in both parietal regions, suggesting the presence of cerebral oedema and focal areas of intracranial haemorrhage or infarcts. Through a subarachnoid catheter the initial intracranial pressure measured was $6 \mathrm{~mm} \mathrm{Hg}$, whereas the mean arterial pressure was $50 \mathrm{~mm} \mathrm{Hg}$.

She remained unstable with frequent bradycardic episodes and there were intermittent increases of intracranial pressure to 20 $30 \mathrm{~mm} \mathrm{Hg}$, despite mannitol. There was further deterioration over the next two days with a labile systemic blood pressure and frequent hypertensive and bradycardic episodes On the third day of admission her electroencephalogram showed electrocerebral silence, her pupils were unresponsive, and she died the next day. Transcranial Doppler ultrasound recordings showed that she had a pressure passive CBFV response to changes in systemic blood pressure (fig 4) with a significant linear correlation between resistance index and mean arterial pressure $(\mathrm{r}=-0.69 ; \mathrm{p}=<0.02)$, which may suggest loss of cerebrovascular autoregulation. Necropsy confirmed congested and swollen cerebral tissue, a compressed ventricular system and thrombosed vessels over both temporal poles with intraparenchymal and subarachnoid haemorrhages.

In contrast, the other two patients who also required intensive care support and treatment for intracranial hypertension did not show a pressure passive CBFV response. This suggests that no loss of cerebrovascular autoregulation occurred during the acutely ill stage in these two patients.

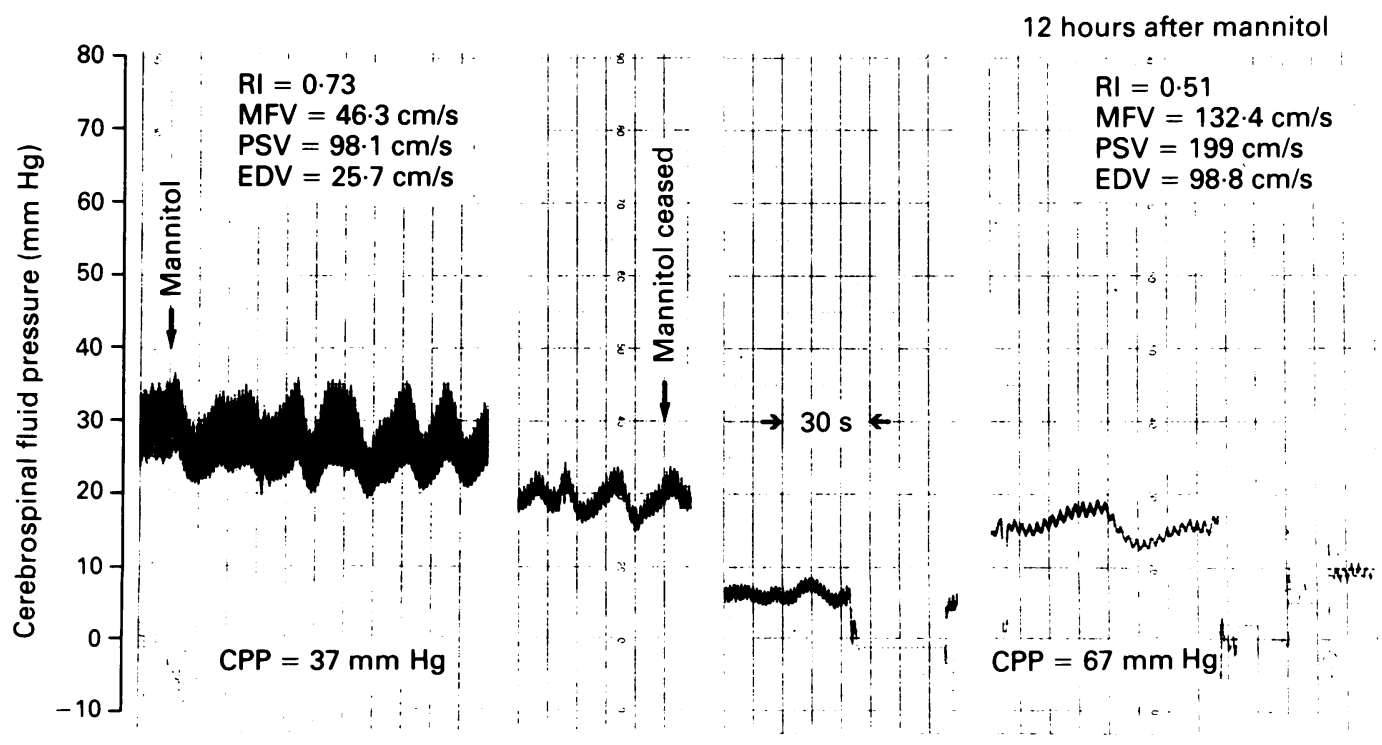

Figure 3 Cerebrospinal fluid pressure recordings with accompanying cerebral perfusion pressure (CPP), resistance index $(R I)$, and mean flow velocity $(M F V)$ values at initial and repeat lumbar puncture ( 12 hours after mannitol infusion) in a 6 year old patient with salmonella meningitis (patient No 17). The cerebrospinal fluid pressure had decreased from 28 to $10 \mathrm{~mm} \mathrm{Hg}$. Cerebral perfusion pressure increased from 37 to $67 \mathrm{~mm} \mathrm{Hg}$, with an accompanying decrease in resistance index from 0.73 to 0.51 and increase in mean flow velocity from $46.3 \mathrm{to} 132 \cdot 3 \mathrm{~cm} / \mathrm{s}$. EDV =end diastolic velocity, PSV = peak systolic velocity. 


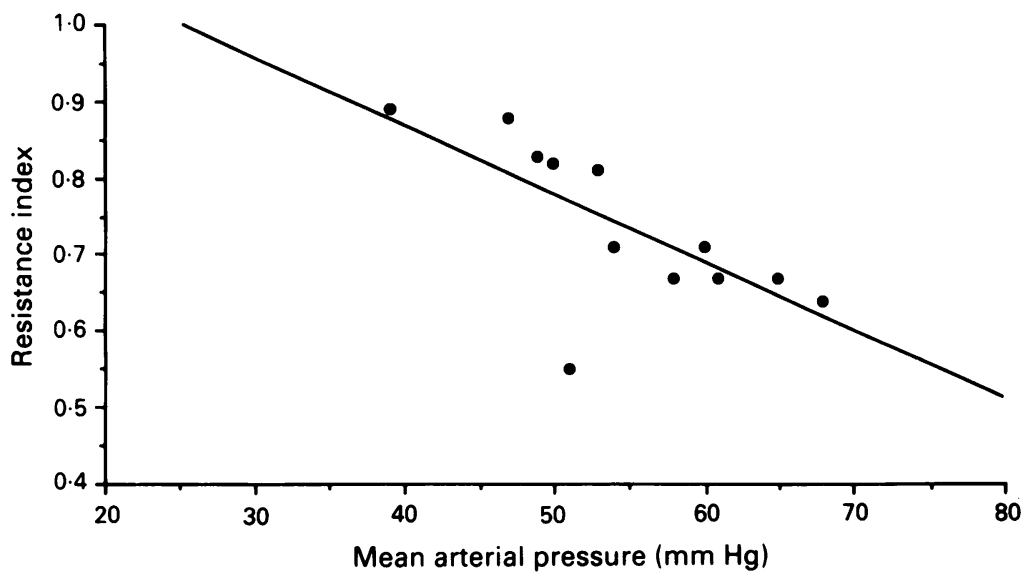

Figure 4 Plot of resistance index against mean arterial pressure values from a 2 week old infant with group $B$ haemolytic streptococcal meningitis who died (patient No 1). This shows a pressure passive $C B F V$ response with a significant linear correlation between resistance index and mean arterial pressure suggesting loss of cerebrovascular autoregulation. $y=1 \cdot 2252-8 \cdot 9354 e-3 x, R^{2}=0 \cdot 476, r=-0 \cdot 69, p<0 \cdot 02$. required and he showed good clinical improvement with resolution of pyrexia and irritability. Sequelae in this patient were focal left sided seizures which were easily controlled by phenytoin and a mild left hemiparesis which was rapidly resolving by the time of discharge.

\section{Discussion}

The pathogenesis of cerebral injury in bacterial meningitis is a complex interaction of a number of inflammatory processes which leads to brain oedema, increased intracranial pressure, and decreased cerebral perfusion. ${ }^{3}$ Cerebral oedema may occur early ${ }^{54}$ and may be vasogenic, cytotoxic, or interstitial in origin. The inflammatory effects on the cerebral microvasculature and macrovasculature can cause arteritis, cortical thrombophlebitis leading to thrombosis, vasospasm, and stenosis with further risk of secondary cerebral infarction or ischaemia. ${ }^{25}$ If the large cerebral arteries are affected there may be serious neurological complications and a poor outcome. ${ }^{26}$ Ventriculomegaly and subdural collections are well recognised complications. ${ }^{27}$

No single modality of monitoring can provide all the required information for understanding the complex balance of intracranial haemodynamic and hydrodynamic processes occurring in ill children with meningitis. Although the need for invasive continuous monitoring of intracranial pressure, cerebral perfusion pressure, or cerebral metabolism is seldom in doubt for the very sick or comatose patient, most children with meningitis do not require intensive care management. In such children, however, a non-invasive means of early detection of deterioration in cerebral haemodynamic trends may help in guiding optimal management. Increased intracranial pressure is still a common feature in the early phase in those who are only moderately ill ${ }^{6}$ and prompt treatment to reduce intracranial pressure-for example, with mannitol-may help prevent further insult from reduced cerebral perfusion pressure. Some patients may develop secondary complications such as subdural effusions, hydrocephalus, or vasculitis and vasospasm and it would be important to monitor the consequent haemodynamic effects of these complications. Xenon computed tomograms have been reported to provide information on regional perfusion states as well as absolute levels of perfusion in meningitis ${ }^{28}$ but cannot be frequently repeated, particularly in young children, because of the risks of radiation exposure. A recent report has suggested that cerebral blood flow itself may be rapidly changing during the process of xenon computed tomography due to xenon induced vasodilatation. ${ }^{29}$

\section{CEREBRAL BLOOD FLOW VELOCITY INDICES}

As an increased resistance index has been shown to be significantly related to increased intracranial pressure ${ }^{10} 111819$ our results suggest that most of our patients had increased intracranial pressure in the early stages of meningitis as the resistance index was significantly increased compared with final predischarge values. With with early clinical response in resistance index values with a gradual return to normal values for age suggested no significant cerebral perfusion compromise and neurosurgical drainage was not required all three patients. Patient No 14 also had a communicating until the subdural fluid culture was confirmed to be negative. 
recovery, the final resistance index values decreased due to a significant increase in the end diastolic velocity with no significant change in the peak systolic velocity. The increased resistance index was thus mainly due to a decreased end diastolic velocity, most likely reflecting increased distal cerebrovascular resistance. This supports the view that in the initial phase increased intracranial pressure is a significant contributing factor to compromised cerebral perfusion through increased cerebrovascular resistance. Lundar et al have also reported from their patients who required neurointensive monitoring that in severe intracranial hypertension when the cerebral perfusion pressure became critically low (less than 40 $\mathrm{mm} \mathrm{Hg}$ ), CBFV waveforms became increasingly pulsatile as systolic blood velocity increased, whereas the diastolic blood velocity was reduced. $^{21}$

Although most of our patients had an initial mean flow velocity within the normal range for their age, there was a significant overall increase in the final values when recovered, associated with a decreased resistance index, thus suggesting that the mean cerebral blood flow may have been relatively reduced initially. With no knowledge of the true middle cerebral artery diameter and wide interpatient variations, however, absolute values of mean flow cannot be determined by this technique, nor can interpatient comparisons be made. It is thus more reliable to use serial CBFV indices to chart haemodynamic trends for each individual patient.

\section{AGE EFFECT: NEONATES VERSUS OLDER INFANTS AND CHILDREN}

In contrast with the differences in $\mathrm{CBFV}$ changes in the two age groups reported by McMenamin and Volpe, ${ }^{15}$ we found nodifference in the pattern of cerebral haemodynamic change between our very young infants and the older group. They suggested the neonatal brain's lesser tendency to respond to infection with oedema, together with a more compliant neonatal cranium as two possible reasons for the absence of increased intracranial pressure in this group. Intracranial pressure in their study was indirectly measured by a transfontanometric method which may be at variance with directly measured levels of intracranial pressure. Necropsy findings on the 2 week old patient (patient No 1) described earlier illustrate that intracranial hypertension and impaired perfusion can be an equally significant complication of meningitis in very young infants with the therapeutic implication that careful attention to the maintenance of adequate cerebral perfusion is just as important at this age.

CBFV CHANGES DUE TO MANNITOL

In all four patients studied there was an improvement in CBFV indices after mannitol infusion. Apart from its osmotic effect in reducing the brain water content, mannitol also reduces blood viscosity and increases local cerebral blood flow. ${ }^{30}$ Decreased resistance index and increased mean flow velocity after mannitol infusion suggests that cerebral perfusion was enhanced in these patients with a reduction in impedance to flow.

\section{PRESSURE PASSIVITY}

We report the occurrence of a pressure passive CBFV response to systemic mean arterial pressure changes only in the neonate who died, suggesting that loss of cerebrovascular autoregulation may be a poor prognostic indicator for survival. Loss of cerebrovascular autoregulation has been reported in a rabbit model with experimental pneumococcal meningitis ${ }^{31}$ and has been previously recognised to be an important link in the pathophysiology of intracranial haemorrhage and cerebral ischaemia in distressed premature infants. ${ }^{32}$ Close attention to maintaining normal levels of systemic blood pressure is therefore required when a pressure passive CBFV response suggests loss of cerebrovascular autoregulation.

In contrast, Ashwal et al reported from their cases with bacterial meningitis that autoregulation was preserved while cerebral blood flow or carbon dioxide reactivity varied among patients and in different regions of the brain in the same patient. ${ }^{28}$ Overall intact autoregulation was assumed in 18 patients as cerebral blood flow values were normal within a range of mean arterial blood pressures from 56 to $102 \mathrm{~mm} \mathrm{Hg}$, though only single measurements from each individual patient were plotted. With only one or two measurements available on most patients due to limitations of repeatability with the xenon computed tomography technique, it may not be entirely reliable to extrapolate that autoregulation would be maintained through a similar systemic arterial pressure range in all patients. Similarly, conclusions on carbon dioxide reactivity in this study were based on only two separate measurements each in seven patients. Data reported by Kirkham from patients with non-traumatic coma where carbon dioxide reactivity was assessed by changes in mean flow velocity suggest that analysis of the shape of the carbon dioxide reactivity curve may be helpful in predicting poor outcome. ${ }^{33}$ Lundar et al, also using transcranial Doppler ultrasound monitoring, reported four patients with poor outcome who also showed pressure passivity in addition to loss of carbon dioxide reactivity. ${ }^{21}$ Only by monitoring haemodynamic changes over a range of systemic arterial pressure and $\mathrm{PaCO}_{2}$ changes for each individual patient can we be certain of the likely cerebrohaemodynamic effects on each patient of therapeutic manoeuvres to alter these factors as there is a complex balance of hydrodynamic and haemodynamic factors in each instance. Transcranial Doppler ultrasound thus provides a practical means of immediate assessment of cerebral haemodynamic carbon dioxide reactivity and autoregulation mechanisms in critically ill patients. Calculated cerebral perfusion pressure changes (derived from mean arterial pressure and intracranial pressure alone do not always reliably predict cerebral blood flow changes; for example, hyperventilation increases the cerebral perfusion pressure by reducing the intracranial 
pressure as a result of reducing cerebral blood flow through vasoconstriction. Ashwal et al highlighted the risk that increasing cerebral perfusion pressure through hyperventilation can paradoxically cause ischaemic insult when cerebral perfusion levels may already be compromised. ${ }^{28}$

\section{VASOSPASM}

Vasculitis causing vasospasm or stenosis leading to further thrombotic, ischaemic damage may occur as a later complication during the acute phase. Mean flow velocity values in any of the basal cerebral arteries which are markedly increased, especially if asymetric, may be suggestive. ${ }^{16}$ Further transcranial Doppler ultrasound examinations would be indicated to determine whether abnormal mean flow velocity values are persistent as alternative invasive investigations such as angiography would be risky in ill children. In many centres magnetic resonance imaging angiography may not be readily accessible. None of our patients had persistently increased mean flow velocity values and thus we assume that none had significantly large cerebral artery stenosis or vasospasm. It is not possible to be certain if the transient increased mean flow velocity values detected in two of our patients were due to transient vasospasm or increased mean flow but neither had any focal clinical signs of ischaemia and the two patients were clinically improving. All our surviving patients had a good outcome with no serious neurological handicap at discharge.

VENTRICULAR DILATATION/SUBDURAL EFFUSIONS Computed tomography has a limited role in early meninigits. ${ }^{34}$ Changes associated with increased intracranial pressure or early cerebral oedema may not be present on early scans as illustrated by one of our patients (patient No 17) and thus a relatively normal scan may be falsely reassuring. Kline and Kaplan reported that although there were abnormal computed tomography findings in 20 of 25 children with bacterial meningitis, the yield of information that was either diagnostically or therapeutically useful was low; positive findings of obvious clinical relevance were only present in two patients. ${ }^{35}$ It may be difficult without accompanying haemodynamic or intracranial pressure data to assess if the clinical significance of complications detected by computed tomography or ultrasound scans, such as hydrocephalus or extra-axial fluid collections, warrant further invasive investigations or management such as surgical shunting or drainage procedures, which are not always appropriate in children with bacterial meningitis. ${ }^{27}$ In our patients with subdural effusions serial CBFV monitoring suggested that there was no significant perfusion compromise as the resistance index decreased to the normal range. Serial resistance index measurements in individual patients can be a reliable indicator for shunting and monitoring cerebrohaemodynamic changes after effective cerebrospinal fluid drainage or diversion. ${ }^{1011}$

Our results suggest that serial CBFV changes provide useful information on cerebrohaemo- dynamic trends in individual children, but careful interpretation of CBFV indices is required for children with meningitis where the pathophysiology is complex. In our experience, as transcranial Doppler ultrasound is a blind technique, the resistance index was more reliable for serial measurements performed on different days as it is, of course, difficult to be certain of always placing the probe on exactly the same position or of insonating the vessel at an identical angle at every examination and thus significant error of measured CBFV changes due to a variable angle of insonation can be wrongly interpreted as true flow velocity changes. ${ }^{36}$ In the early phase when increased intracranial pressure may be present, the resistance index is more useful and resistance index values greater than 0.65 for older infants and children and greater than 0.8 in neonates and young infants suggest that there may be significant perfusion compromise, especially when mean flow velocity values are also less than normal. Reported values suggesting increased resistance index in different clinical conditions $^{1011} 1837$ as well as reported normal ranges appear to be fairly similar and reproducible, supporting this as a reliable index.

We did not find serial monitoring of mean flow velocity from day to day to be as consistent in our patients, but suggest that this index would be more useful as a means to detect and monitor complications of basal cerebral artery vasospasm or stenosis. Repeated examinations with left/right comparisons can be made, especially if focal signs are clinically detected. In the intensive care situation where a transcranial Doppler ultrasound probe can be left in a fixed position, mean flow velocity changes may then be a reliable guide to changes in mean volume flow over a short period for assessment of pressure passivity or carbon dioxide reactivity, ${ }^{21}$ assuming that no significant change in calibre of the insonated vessel is likely to occur.

In summary, we report that improvement in cerebral blood flow velocity with decreased resistance index due to increased end diastolic velocity and increased mean flow velocity occurs with resolution of pyogenic meningitis. This suggests that relatively decreased perfusion may occur during the acute phase in children with meningitis who are only moderately ill. Increased intracranial pressure causing increased cerebrovascular resistance is likely to be a significant contributing factor. There was no difference in CBFV patterns of neonates or older infants and children, emphasising that equally careful attention to factors which influence cerebral perfusion is required for neonatal patients who generally have a much poorer outcome. ${ }^{1}$ Loss of cerebrovascular autoregulation as shown by a pressure passive CBFV response may be a poor prognostic indicator. We suggest that transcranial Doppler ultrasound can be a useful non-invasive method of monitoring cerebral haemodynamic changes in children with meningitis.

We are grateful to the Earl of Elgin and Kincardine and the Trustees Savings Bank Foundation, Scotland for supporting research in the department of paediatric neurology, Royal 
Hospital for Sick Children, Edinburgh. We are also grateful to all our paediatric consultant colleagues who have cooperated with this study and kindly agreed to letting us report the patients in their care.

1 de Louvois J, Blackbourn J, Hurley R, Havery D. Infantile meningitis in England and Wales: a two year study. Arch Dis Child

2 Pomeroy SL, Holmes SJ, Dodge PR, Feigin RD. Seizures and other neurologic sequelae of bacterial meningitis in children. $N$ Engl F Med 1990;323:1651-7.

3 Tunkel AR, Wispelwey B, Scheld WM. Bacterial meningitis: recent advances in pathophysiology and treatment. Ann Intern Med 1990;112:610-23.

4 Goitein KJ, Tamir I. Cerebral perfusion pressure in central nervous infections of infancy and childhood. 7 Pediat 1983;103:40-3.

5 Rebaud P, Berthier JC, Hartemann E, Floret D. Intracranial pressure in childhood central nervous system infections. Intensive Care Medicine 1988;14:522-5.

6 Minns RA, Engleman HM, Stirling H. Cerebrospinal fluid pressure in pyogenic meningitis. Arch Dis Child 1989;64: $814-20$.

7 Pike MG, Wong PKH, Bencivenga R, et al. Elecrophysiologic studies, computed tomography, and neurologic outcome in acute bacterial meningitis. F Pediatr 1990;116:702-6.

8 Aaslid R, Markwalder TM, Nornes H. Noninvasive transcranial Doppler ultrasound recording of flow velocity in basal cerebral vessels. $\mathcal{F}$ Neurosurg 1982;57:769-74.

9 Hill A, Volpe JJ. Decrease in pulsatile flow in the anterior cerebral arteries in infantile hydrocephalus. Pediatrics 1982; 69:4-7.

10 Chadduck WM, Seibert JJ. Intracranial duplex Doppler: practical uses in pediatric neurology and neurosurgery. practical uses in pediatric neur
$f$ Child Neurol 1989;4:S77-86.

11 Goh D, Minns RA, Pye SD, Steers AJW. Cerebral blood flow velocity changes after ventricular taps and ventriculoperitoneal shunting. Childs Nerv Syst 1991;7:452-7.

12 Seiler RW, Aaslid R. Transcranial Doppler for evaluation of cerebral vasospasm. In: Aaslid R, ed. Transcranial Doppler sonography. New York: Springer Verlag, 1986:118-31.

13 Hassler W, Steinmetz H, Gawlowski J. Transcranial Doppler ultrasonography in raised intracranial pressure and in intracranial circulatory arrest. F Neurosurg 1988;68:745-51.

14 Raju TNK. Cerebral Doppler studies in the fetus and newborn infant. 7 Pediatr 1991;119:165-74.

15 McMenamin JB, Volpe JJ. Bacterial meningitis in infancy: effects on intracranial pressure and cerebral blood flow effects on intracranial pressure and
velocity. Neurology 1984;34:500-4.

16 Bode $\mathrm{H}$, Harders $\mathrm{A}$. Transient stenoses and occlusion of main cerebral arteries in children-diagnosis and control of therapy by transcranial Doppler sonography. Eur $\mathcal{F}$ Pediatr therapy by transcran

17 Pourcelot L. Diagnostic ultrasound for cerebral vascular diseases. In: Donald I, Levi S, eds. Present and future of diagnostic ultrasound. Rotterdam: Kooyker, 1976:141-7.

18 Klingelhofer J, Conrad B, Benecke R, Sander D, Markakis E. Evaluation of intracranial pressure from transcranial Doppler studies in cerebral disease. 7 Neurol 1988;235. $159-62$.
19 Seibet JJ, McCowan TC, Chadduck WM, et al. Duplex pulsed Doppler US versus intracranial pressure in the neonate: clinical and experimental studies. Radiology 1989 171:155-9.

20 Bishop CCR, Powell S, Rutt D, Browse NL. Transcranial Doppler measurement of middle cerebral artery blood flow velocity: a validation study. Stroke 1986;17:913-5.

21 Lundar T, Lindegaard K-F, Nornes $H$. Continuous recording of middle cerebral artery blood velocity in clinical neurosurgery. Acta Neurochir (Wien) 1990;102:85-90.

22 Bode $\mathrm{H}$, Wais U. Age dependence of flow velocities in basal cerebral arteries. Arch Dis Child 1988;63:606-11.

23 Archer LNJ, Evans DH, Paton JY, Levene MI. Controlled hypercapnia and neonatal cerebral artery Doppler ultrasound waveforms. Pediatr Res 1986;20:218-21.

24 Pfister HW, Koedel U, Haberl RL, et al. Microvascular changes during the early phase of experimental bacterial meningitis. F Cereb Blood Flow Metab 1990;10:914-22.

25 Raimondi AJ, Di Rocco C. The physiopathogenetic basis for the angiographic diagnosis of bacterial infections of the brain and its coverings in children. I. Leptomeningitis. Childs Brain 1979;5:1-13.
Chin

26 Igarashi M, Gilmartin RC, Gerald B, Wilburn F, Jabbour JT Cerebral arteritis and bacterial meningitis. Arch Neurol 1984;41:531-5.

27 Snyder RD. Ventriculomegaly in childhood bacterial meningitis. Neuropediatrics 1984;15:136-8.

28 Ashwal S, Stringer W, Tomasi L, Schneider S, Thompson J Perkin R. Cerebral blood flow and carbon dioxide reactivity in children with bacterial meningitis. 7 Pediatr 1990;117: 523-30.

29 Giller CA, Purdy P, Lindstrom WW. Effects of inhaled stable xenon on cerebral blood flow velocity. AfNR 1990;11: 177-82.

30 Muizelaar JP, Wei EP, Kontos HA. Mannitol causes compensatory vasoconstriction and vasodilatation in response to blood viscosity changes. 7 Neurosurg 1983;59:822-8.

31 Tureen JH, Dworkin RJ, Kennedy SL, Sachdeva M, Sande MA. Loss of cerebrovascular autoregulation in experimental meningitis in rabbits. $\mathcal{F}$ Clin Invest 1990;85:577-81.

32 Lou HC, Lassen NA, Friis-Hansen B. Impaired autoregulation of cerebral blood flow in the distressed newborn infant f Pediatr 1979;94:118-21.

33 Kirkham FJ. Intracranial pressure and cerebral bloodflow in non-traumatic coma in childhood. In: Minns RA, ed Problems of intracranial pressure in childhood. Clinics in developmental medicine Nos 113/114. London: MacKeith Press, 1991:283-348.

34 Haslam RHA. Role of computed tomography in the early management of bacterial meningitis. $\mathcal{f}$ Pediatr 1991;119: man-9.

35 Kline MW, Kaplan SL. Computed tomography in bacterial meningitis of childhood. Pediatr Infect Dis f 1988;7:855-7.

36 Finn JP, Quinn MW, Hall-Craggs MA, Kendall BE. Impact of vessel distortion on transcranial Doppler velocity measurements: correlation with magnetic resonance imaging. $\mathcal{F}$ Neurosurg 1990;73:572-5

37 Klingelhofer J, Sander D, Holzgraefe M, Bischoff C, Conrad B. Cerebral vasospasm evaluated by transcranial Doppler ultrasonography at different intracranial pressures. F Neurosurgy 1991;75:752-8. 